\title{
INFLUENCES OF DISCHARGE REDUCTIONS ON SALT WATER INTRUSION AND RESIDUAL CIRCULATION IN DANSHUEI RIVER
}

\author{
Wen-Cheng Liu \\ Department of Civil and Disaster Prevention Engineering, National United University, Miao-Li 36003, Taiwan, R.O.C., \\ wcliu@nuu.edu.tw \\ Wei-Bo Chen \\ Department of Bioenvironmental Systems Engineering, National Taiwan University, Taipei 10617, Taiwan, R.O.C. \\ Ming-Hsi Hsu \\ Department of Bioenvironmental Systems Engineering, National Taiwan University, Taipei 10617, Taiwan, R.O.C.
}

Follow this and additional works at: https://jmstt.ntou.edu.tw/journal

Part of the Engineering Commons

\author{
Recommended Citation \\ Liu, Wen-Cheng; Chen, Wei-Bo; and Hsu, Ming-Hsi (2011) "INFLUENCES OF DISCHARGE REDUCTIONS ON SALT \\ WATER INTRUSION AND RESIDUAL CIRCULATION IN DANSHUEI RIVER," Journal of Marine Science and Technology. \\ Vol. 19: Iss. 6, Article 3. \\ DOI: $10.51400 / 2709-6998.2201$ \\ Available at: https://jmstt.ntou.edu.tw/journal/vol19/iss6/3 \\ This Research Article is brought to you for free and open access by Journal of Marine Science and Technology. It has been \\ accepted for inclusion in Journal of Marine Science and Technology by an authorized editor of Journal of Marine Science and \\ Technology.
}




\section{INFLUENCES OF DISCHARGE REDUCTIONS ON SALT WATER INTRUSION AND}

RESIDUAL CIRCULATION IN DANSHUEI RIVER

\section{Acknowledgements}

This study was supported in part by National Science Council, Taiwan, under grant No.

97-2625-M-239-001. The financial support is greatly appreciated. The authors also thank the Taiwan Water Resources Agency for providing the measured data for model validation. 


\title{
INFLUENCES OF DISCHARGE REDUCTIONS ON SALT WATER INTRUSION AND RESIDUAL CIRCULATION IN DANSHUEI RIVER
}

\author{
Wen-Cheng Liu*, Wei-Bo Chen**, and Ming-Hsi Hsu**
}

Key words: hydrodynamic model, salt water intrusion, residual circulation, Danshuei River estuarine system, reservoir construction.

\begin{abstract}
A three-dimensional, unstructured grid, hydrodynamic model was established and applied to study the salt water intrusion and residual circulation in the Danshuei River estuarine system of northern Taiwan. The construction of two reservoirs (i.e. Shihmen Reservoir and Feitsui Reservoir) and water diversion in the upper reaches of the river system significantly reduces the freshwater inflow. The changes had contributed farther to the intrusion of tidal flow and salt water in the upstream direction. The model was validated with available hydrographic data measured in 2001 then used to probe the change in salt water intrusion as a result of reservoir construction. The model simulations indicate that more tidal energy propagates into the estuarine system after reservoir construction because of the substantial increase in river crosssections and decrease in freshwater discharges. The residual circulation before reservoir construction is weaker than that after reservoir construction. The limits of salt water intrusion after reservoir construction extend farther inland $3.5 \mathrm{~km}$ than those before reservoir construction under mean flow condition. This case study offers the quantitative estimate of the salinity and residual circulation changes due to human interface in this nature system.
\end{abstract}

\section{INTRODUCTION}

Reservoirs are the most important and effective water storage facilities in modifying uneven distribution of water both in space and time. They not only provide water, hydroelectric energy and irrigation, but also smooth out extreme

Paper submitted 02/25/10; revised 06/16/10, 08/23/10; accepted 09/24/10. Author for correspondence: Wen-ChengLiu (e-mail: wcliu@nuu.edu.tw).

*Department of Civil and Disaster Prevention Engineering, National United University, Miao-Li 36003, Taiwan, R.O.C.

**Department of Bioenvironmental Systems Engineering, National Taiwan University, Taipei 10617, Taiwan, R.O.C. inflows to mitigate floods or droughts. However, they naturally led to the imposition of man-made changes on rivers, such as reservoir regulation, bathymetric change, and freshwater withdrawals. In these cases, upstream changes of the river runoff will inevitably have consequences on the estuarine portion of the river.

Although river management has commonly occurred over the past 50 years, most studies have focused on the short or medium term behavior of estuarine flows, few studies have been conducted and little is known about the long-term estuarine response associated with river management schemes $[6,7,12]$. For these reasons, there is a need for a numerical modeling in conjunction with any estuary-related management plans. Numerical models have become important tools to assess the response of natural systems to changes in environmental regulation of engineering facilities.

Several reports have been documented with threedimensional model to evaluate the response of natural systems to environmental changes. Mao et al. [11] adopted threedimensional baroclinic model, HAMburg Shelf Ocean Model (HAMSOM), to simulate the salinity variations in Bohai Sea that was influenced by the surrounding rivers or the intrusions of the North Yellow Sea Water. An et al. [1] applied threedimensional model, ECOMSED, to investigate the influence of Three Georges Project on saltwater intrusion in the Yangtz River estuary in China. Oliveira et al. [13] used the threedimensional hydrodynamic model, ELCIRC, to study natural and artificial morphological changes in tidal inlet propagation and flushing properties in the lagoon. Sierra et al. [15] used the MIKE 21 package to probe the effect of freshwater reduction on salt wedge dynamics in Ebro River due to construction of several dams. Huang and Spaulding [5] applied a threedimensional hydrodynamic model, POM, to determine residence time in response to the change of freshwater input in Apalachicola Bay.

The Danshuei River estuary (Fig. 1) is the largest estuarine system in northern Taiwan. The tidal influence spans a total length of about $82 \mathrm{~km}$, encompassing the entire length of the Danshuei River and the downstream reaches of its three major tributaries: the Tahan Stream, Hsintien Stream, and Keelung River. Tidal propagation is the major dominant mechanism controlling the water surface elevation, and ebb and flood 


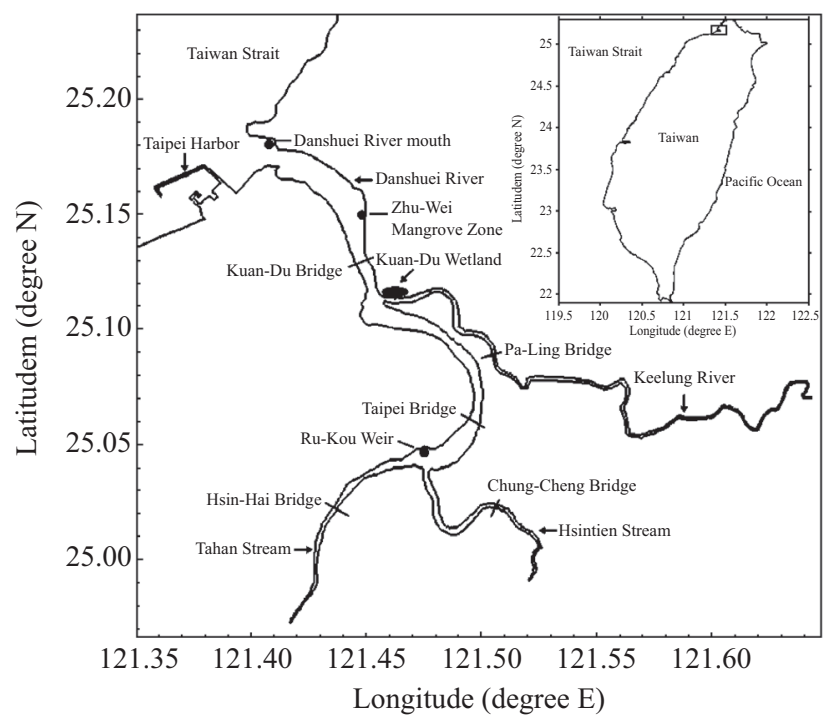

Fig. 1. Map of the Danshuei River estuarine system.

flows. The M2 tide is the primary tidal constituent at the river mouth, with a tidal range of $2.17 \mathrm{~m}$ at mean tide, and up to $3 \mathrm{~m}$ at spring tide. Because of the cross-sectional contraction and wave refraction, the mean tidal range may reach a maximum $2.39 \mathrm{~m}$ within the system. The phase relationship between tidal elevation and tidal flow is close to standing wave characteristics [4].

Two reservoirs, Feitsui Reservoir and Shihman Reservoir, were built in the upriver reaches of the Danshuei River system. Feitsui Reservoir, completed in 1987, had an initial design capacity of $4.06 \times 108 \mathrm{~m}^{3}$ was primarily designed to provide domestic water supply to the Taipei metropolitan area with a population over 5 million. The dam site of the Feitsui Reservoir is located at the lower end of the Peishih Stream, a tributary of the Hsintien Stream, and is approximately $30 \mathrm{~km}$ away from Taipei City. Shihmen Reservoir was completed in 1964 and situated at the upper end of the Tahan Stream. This multipurpose reservoir supplies water to the rice fields of northern Taiwan and to Taipei during the dry season. Covering $8 \mathrm{~km}^{2}$, this man-made reservoir also generates electricity of $87,400 \mathrm{~kW}$ for the island's insatiable demand. Another vital function of these two reservoirs is to provide flood control during the typhoon season. Fig. 2(a) presents flow duration curves in the Tahan Stream before and after the Shihmen Reservoir construction. Fig. 2(b) shows flow duration curves in the Hsintien Stream before and after the Feitsui Reservoir construction. These figures reveal that the river discharges have dramatically reduced after the reservoirs were built.

In this study, a three-dimensional hydrodynamic model was established and applied to study the Danshuei River estuarine system. The model has been validated with 2001 measured data. The model was then used to simulate salt water intrusion and residual circulation under both the current conditions and the prereservoir conditions. The modeling results indicate that the reservoir construction has critical impacts on salt water
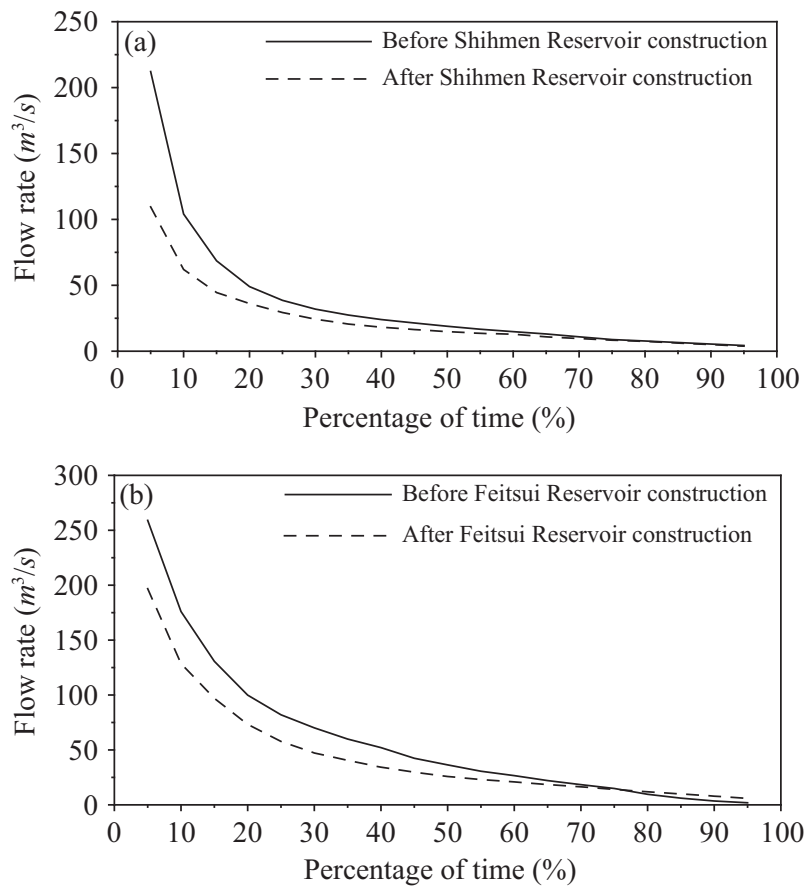

Fig. 2. Comparison of flow duration curves before and after reservoir construction in the (a) Tahan Stream and (b) Hsintien Stream.

intrusion and residual circulation in the Danshuei River estuarine system.

\section{MODEL DESCRIPTION}

A three-dimensional semi-implicit Eulerian-Lagrangian finite-element model (SELFE) [20, 21] was implemented to simulate the Danshuei River estuarine system and its adjacent coastal sea. SELFE solves the Reynolds-stress averaged Navier-Stokes equations consisting of conservation laws for mass, momentum and salt, under the hydrostatic and the Boussinesq approximations, to yield the free-surface elevation, threedimensional water velocity and salinity:

$$
\begin{gathered}
\nabla \cdot \vec{u}+\frac{\partial W}{\partial z}=0 \\
\frac{\partial \eta}{\partial t}+\nabla \cdot \int_{-h}^{\eta} \vec{u} d z=0
\end{gathered}
$$

$$
\begin{aligned}
& \frac{D \vec{u}}{D t}=\overrightarrow{\mathbb{F}}-g \nabla \eta+\frac{\partial}{\partial z}\left(\nu \frac{\partial \vec{u}}{\partial z}\right) \\
& \overrightarrow{\mathbb{F}}=-f \vec{k} \times \vec{u}+\alpha g \nabla \hat{\psi}-\frac{1}{\rho_{0}} \nabla P_{A}-\frac{g}{\rho_{0}} \int_{z}^{\eta} \nabla \rho d \zeta+\nabla \cdot(\mu \nabla u) \\
& \frac{D S}{D t}=\frac{\partial}{\partial z}\left(\kappa \frac{\partial S}{\partial z}\right) \\
& \rho=\rho_{0}(p, S)
\end{aligned}
$$


where $(x, y)$ is the horizontal Cartesian coordinates; $z$ is the vertical coordinate and positive upward; $\nabla=\left(\frac{\partial}{\partial x} \vec{i}, \frac{\partial}{\partial y} \vec{j}\right) ; t$ is time; $\eta(x, y, t)$ is free-surface elevation; $h(x, y)$ is bathymetric depth; $\vec{u}(x, y, z, t)$ is horizontal velocity, with Cartesian components $(U, V) ; W$ is vertical velocity; $f$ is the Coriolis factor; $g$ is acceleration of gravity; $\hat{\psi}(\phi, \lambda)$ is earth tidal potential; $\alpha$ is effective Earth elasticity factor; $\rho(x, t)$ is water density with reference value $\rho_{0}=1025 \mathrm{~kg} / \mathrm{m}^{3} ; P_{A}(x, y, t)$ is atmospheric pressure at the free surface; $p$ is pressure; $S$ is salinity; $v$ is vertical eddy viscosity; $\mu$ is horizontal eddy viscosity and $\kappa$ is vertical eddy diffusivity for salinity.

The vertical boundary conditions for the momentum equation, especially the bottom boundary condition, play an important role in the SELFE numerical formulation, as it involves the unknown velocity. In fact, as a crucial step in solving the differential system, SELFE uses the bottom condition to decouple the free-surface Eq. (2) from the momentum Eq. (3).

At the water surface, the balance between the internal Reynolds stress and the applied shear stress yields:

$$
v \frac{\partial \vec{u}}{\partial z}=\overrightarrow{\tau_{w}} \text { at } z=\eta
$$

where the specific stress $\tau_{w}$ can be parameterized using either the approach Zeng et al. [19] or that of Pond and Pickard [14].

The boundary condition at the bottom plays an important in SELFE formulation, as it involves the unknown velocity. Specifically, at the bottom, the no-slip condition $(U=V=0)$ is usually replaced by a balance between the internal Reynolds stress and the bottom frictional stress, ie.,

$$
v \frac{\partial \vec{u}}{\partial z}=\tau_{b} \text { at } z=-h
$$

where the bottom stress is $\overrightarrow{\tau_{b}}=C_{D}\left|u_{b}\right| \overrightarrow{u_{b}}$.

The velocity profile inside the bottom boundary layers obeys the logarithmic law:

$$
\vec{u}=\frac{\ln \left[(z+h) / z_{0}\right]}{\ln \left(\delta_{b} / z_{0}\right)} \overrightarrow{u_{b}}, \quad\left(z_{0}-h \leq z \leq \delta_{b}-h\right)
$$

which is subject to be smoothly matched to the exterior flow. In Eq. (8), $\delta_{b}$ is the thickness of the bottom computational cell, $z_{0}$ is the bottom roughness, and $u_{b}$ is the bottom velocity, measured at the top of the bottom computational cell. The Reynolds stress inside the boundary layer is derived from Eq. (8) as:

$$
v \frac{\partial \vec{u}}{\partial z}=\frac{v}{(z+h) \ln \left(\delta_{b} / z_{0}\right)} \overrightarrow{u_{b}}
$$

From the turbulence closure theory [17], the eddy viscosity can be expressed by:

$$
v=\sqrt{2 s_{m}} K^{1 / 2} l
$$

where the stability function, the turbulent kinetic energy, and the macroscale mixing length are given by:

$$
\begin{aligned}
& S_{m}=g_{2} \\
& K=\frac{1}{2} B_{1}^{2 / 3} C_{D}\left|u_{b}\right|^{2} \\
& l=\kappa_{0}(z+h)
\end{aligned}
$$

In Eq. (11), $\kappa_{0}=0.4$ is the von Karman's constant, and $g_{2}$ and $B_{1}$ are constants with $g_{2} B_{1}^{1 / 3}=1$. Tennekes et al. [16] reported the Reynolds stress is not constant value inside the boundary layer. Hanert et al. [3] developed and compared numerical discretizations that explicitly take into account the logarithmic behavior of the velocity filed in the oceanic bottom boundary layer. This is achieved by discetizing the governing equations by means of the finite element method and either enriching or modifying the set of shape functions used to approximate the velocity field. They found that their proposed method can capture the velocity filed in the bottom boundary layer. However Eq. (12) was implemented in a straightforward way in the finite element model. In this study, the constant was however adopted for simplification, yielding

$$
v \frac{\partial \vec{u}}{\partial z}=\frac{\kappa_{0}}{\ln \left(\delta_{b} / z_{0}\right)} C_{D}^{1 / 2}\left|u_{b}\right| \overrightarrow{u_{b}},\left(z_{0}-h \leq z \leq \delta_{b}-h\right)
$$

where the drag coefficient, calculated from Eqs. (6), (7) and (12), is

$$
C_{D}=\left(\frac{1}{\kappa_{0}} \ln \frac{\delta_{b}}{z_{0}}\right)^{-2}
$$

Eq. (12) indicates that the vertical viscosity term in the momentum equation vanishes inside the boundary layer, and this is used here.

Numerical efficiency and accuracy consideration dictates the numerical formulation of SELFE. SELFE solves the differential equation system with finite-element and finitevolume schemes. No mode splitting is used in SELFE, thus eliminating the errors associated with the splitting between internal and external modes. Semi-implicit schemes applied to all equations; the continuity and momentum equations (Eqs. (2) and (3)) are solved simultaneously, thus bypassing the most severe stability restrictions. A key step in SELFE is to decouple the continuity and momentum equations via the bottom boundary layers. SELFE uses an Eulerian-Lagrangian 


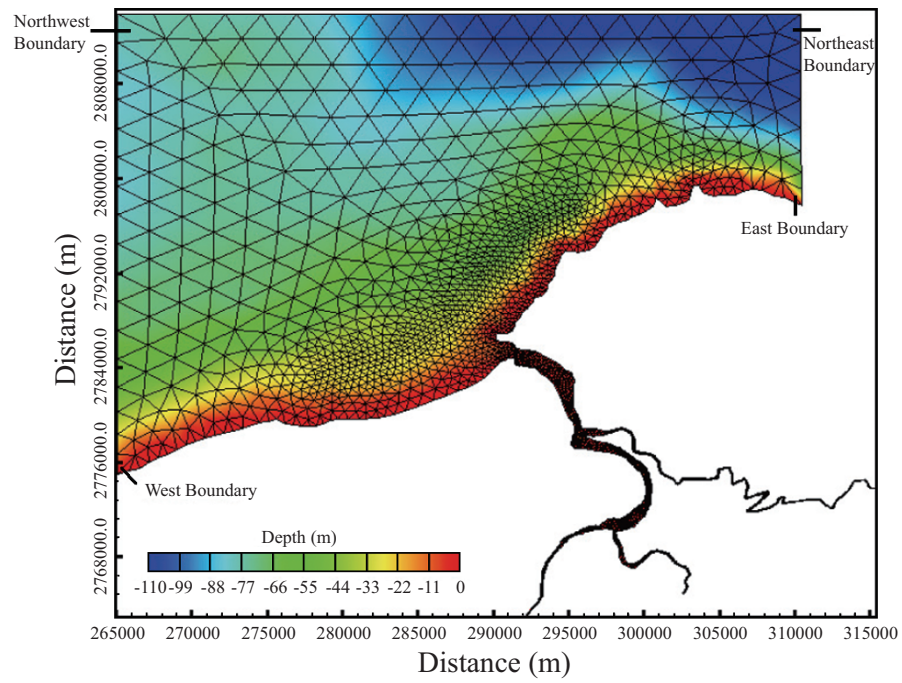

(a)

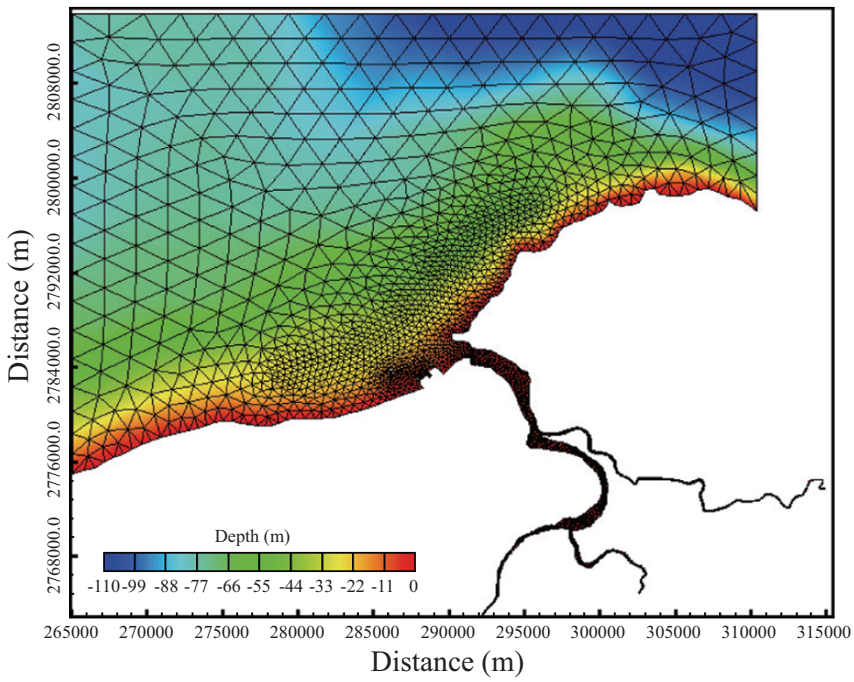

(b)

Fig. 3. Unstructured grid representing in the modeling domain (a) before reservoir construction and (b) after reservoir construction.

method (ELM) to treat the advection in momentum equation, thus further relaxing the numerical stability constrains. The advection terms in the transport equation (Eq. (4)) is treated with finite-volume upwind method.

Bottom topography is an important factor that affects the flow properties in environmental modeling. Hence an accurate representation of bottom topography by the model grid is critical to successful estuarine and coastal modeling [2]. This is particularly true for the complex Danshuei River estuarine system and its adjacent coastal sea. The model grid must represent accurately the characteristics of the Danshuei River estuarine system that constitutes the model domain.

In this study, the bottom topography data in the coastal sea and Danshuei River estuarine system were obtained from the National Center for Ocean Research and Water Resources Agency, Taiwan. The deepest depth within the study area is $110 \mathrm{~m}$ (below the mean sea level) near the northeast corner of the model in the coastal sea. The model mesh for the Danshuei River estuarine system and its adjacent coastal sea consists of 6344 and 6335 polygons before and after reservoir construction, respectively (Fig. 3). Higher resolution grids are used in the Danshuei River estuary, and rough grids are used in the coastal sea. For the hybrid "SZ" vertical grid, 10 z-level and 10 evenly-spaced S-levels were used. For this model grid, a 120 seconds time step was used in simulations with no sign of numerical instability.

\section{MODEL VALIDATION}

To ascertain the model accuracy for practical applications, a large set of observation data is used to validate the model and to verify its capability to predict the water surface elevation, tidal current, and salinity in this study.

\section{Water Surface Elevation and Tidal Current}

The model validation of water surface elevation and tidal current was conducted with daily freshwater discharge data from upriver of the Tahan Stream, Hsintien Stream, and Keelung River in 2001. The open boundaries at the coastal sea were specified by six tidal constituents $\left(M_{2}, S_{2}, N_{2}, K_{1}, O_{1}\right.$ and $S_{a}$ ). The model was run for a one-year simulation. Fig. 4 compares the computed surface elevation and measured data with time series at six stations in July. In general, the modeling results faithfully reproduce the water level variations.

To validate the model in calculating tidal currents, an intensive survey of current speed was conducted in five transects on April 24, 2001. Half-hourly current speed was measured by personnel on boats for a period of 13 daylight hours. Velocity data were taken with handheld current meters that measure current magnitude but not direction. The data were recorded by hand, and the "ebb or flood" direction was noted with visual observations. There was some uncertainty in assigning current direction during the period around slack tides. To compare the measured and computed velocities, the computed velocity in the horizontal plane was transferred to the velocity along the channel. Fig. 5 presents the comparison of the time series data of velocity along the channel (i.e., axial velocity) for April 24, 2001. The model satisfactorily predicted the velocity along the channel. It was found that the flood tidal current is weaker with shorter duration than the ebb tidal current in the estuary. This was attributed to the tidal asymmetry caused by both bathymetry and the interaction between the incoming tide and river flow.

\section{Time-series Salinity}

Salinity distributions reflect the combined results of all processes, including density circulation and mixing processes. These in turn control the density circulation and modify the mixing processes. The evaporation and precipitation were not taken into account during the salinity simulations, because the 

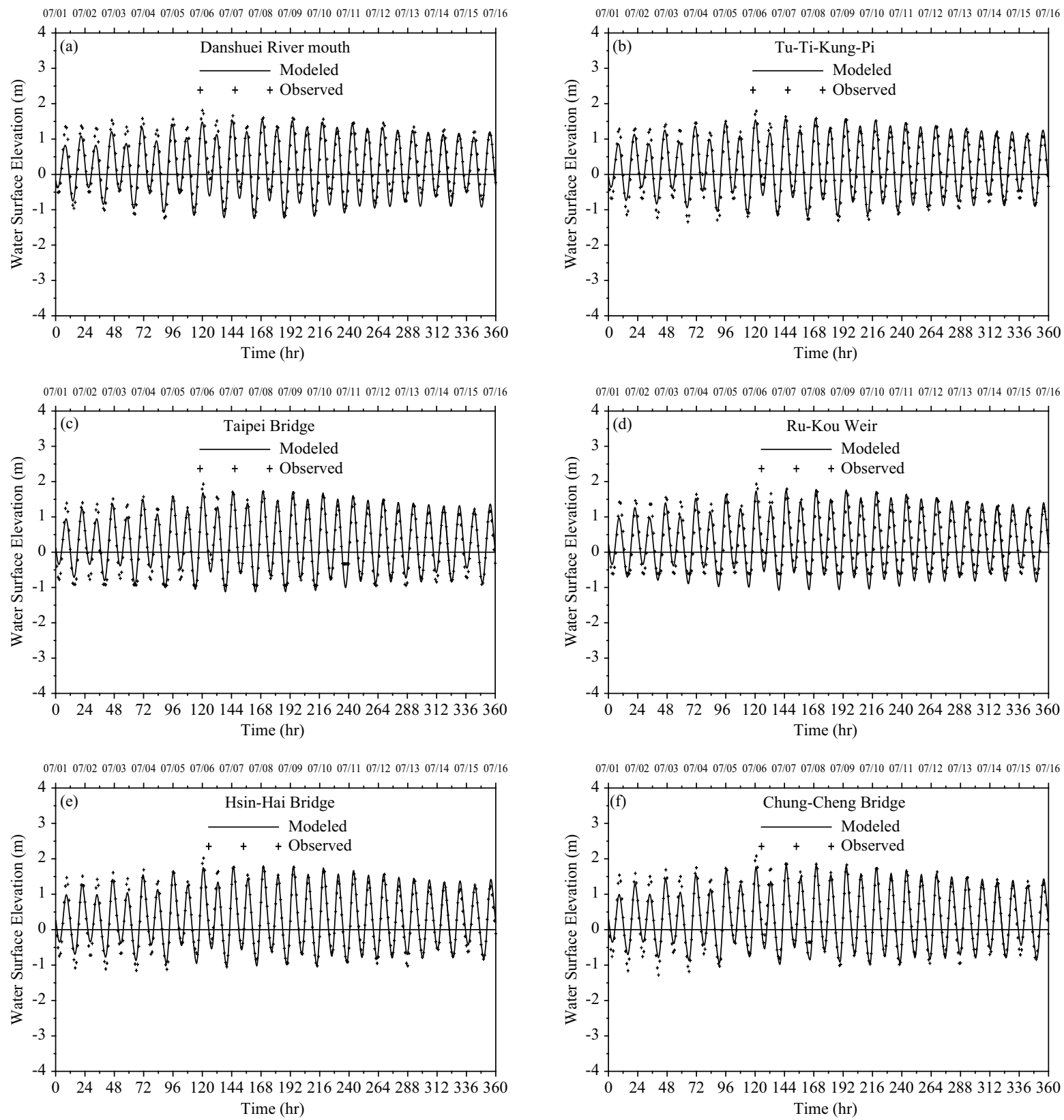

Fig. 4. Comparison of computed water surface elevation with observed data during period of July 1 to 15 , 2001 at (a) Danshuei River mouth, (b) Tu-Ti-Kung-Pi, (c) Taipei Bridge, (d) Ru-Kou Weir, (e) Hsin-Hai Bridge and (f) Chung-Cheng Bridge.

freshwater flux at air-sea interface was not important in the estuarine system.

A limited long-term salinity time series exists for the Zhu-Wei mangrove zone, having been collected by the Taiwan Industrial Technology Institute and this time series was used for model validation. The salinities of open boundaries in the coastal sea were set to 35 psu (practical salinity unit). At the heads of the three tributaries the salinity boundary conditions were set to $0 \mathrm{psu}$ together with the specification of daily freshwater discharges. The initial salinity distribution varies with the distance from the Danshuei River mouth. It means that the salinity is higher near the Danshuei River mouth and decreases gradually away from river mouth. The spinning-up time of the model is one month to reach quasi-equilibrium.

Fig. 6 shows the simulated salinity time series compared very favorably with the salinity measurements at the Zhu-Wei mangrove zone. The dynamic variation of observed salinity between 5 psu and 30 psu over a tidal cycle was reproduced by the model (Fig. 6(b)). Salinity distributions reflect the combined results of all processes, including density circulation and mixing processes. These in turn control the density circulation and modify the mixing processes. However the simulated salinity can not really catch the maximum or minimum salinity of observation. It may be the reason that the calculated eddy 

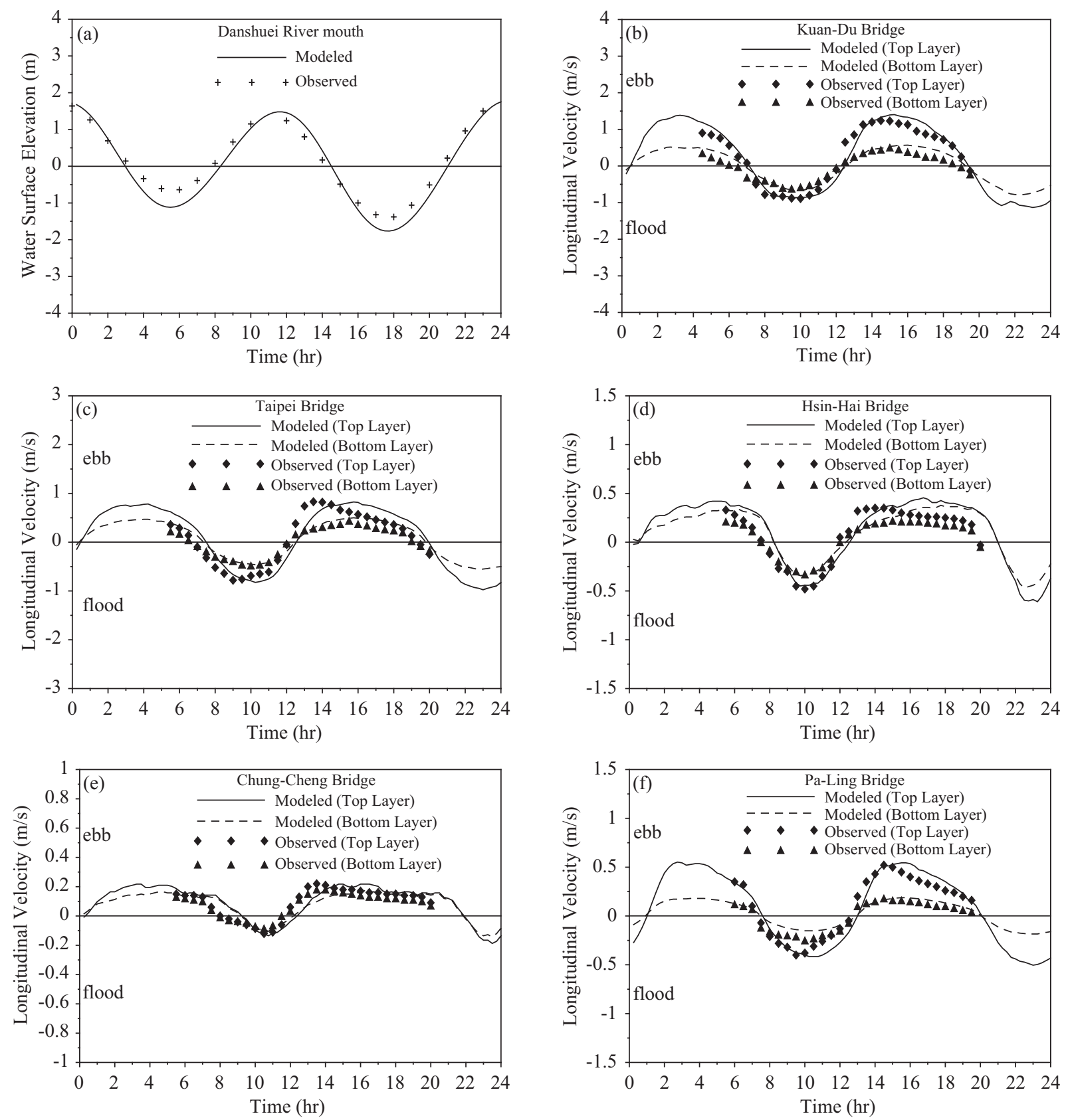

Fig.5. (a) Water surface elevation at Danshuei River mouth and comparison of computed longitudinal velocity with time series data on April 24, 2001 at (b) Kuan-Du Bridge, (c) Taipei Bridge, (d) Hsin-Hai Bridge, (e) Chung-Cheng Bridge and (f) Pa-Ling Bridge.

diffusivity with turbulent closure model needs to be carefully investigated. As the freshwater discharges increase, the salinity sharply decreases to zero during the September 16 to 20, 2001 (Fig. 6(a)). Overall, the SELFE model reflected the large dynamic variations of salinity over a tidal cycle and a decreasing trend of salinity as freshwater increased.

\section{MODEL APPLICATION AND EVALUATION}

The validated model was used to investigate the salinity distribution before reservoir construction and under present conditions, respectively. The earliest available bathymetric data were collected in 1969 , a time between the construction of Shihmen Reservoir and Feitsui Reservoir. These data were used to represent the geometric conditions prior to reservoir construction. To avoid the wind stress effect, the model simulations have not included the wind field.

\section{Effect on Salt Intrusion}

To examine the salinity distributions pre- and post-reservoir construction, respectively, model simulations were conducted using six constituent tides at the open sea boundary. Amplitudes 
Table 1. River discharge at upstream boundaries before and after reservoir construction.

\begin{tabular}{|c|c|c|c|c|}
\hline Conditions & $\begin{array}{c}\text { Upstream } \\
\text { boundaries }\end{array}$ & $\begin{array}{c}\mathrm{Q}_{\mathrm{m}}\left(\mathrm{m}^{3} / \mathrm{s}\right) \\
\text { (mean flow) }\end{array}$ & $\begin{array}{c}\mathrm{Q}_{50}\left(\mathrm{~m}^{3} / \mathrm{s}\right) \\
\text { (medium flow) }\end{array}$ & $\begin{array}{c}\mathrm{Q}_{75}\left(\mathrm{~m}^{3} / \mathrm{s}\right) \\
(\text { low flow) }\end{array}$ \\
\hline $\begin{array}{c}\text { Before } \\
\text { reservoir } \\
\text { construction }\end{array}$ & Tahan Stream & 60.03 & 20.95 & 12.87 \\
Hsintien Stream & 80.80 & 40.40 & 17.86 \\
Keelung River & 25.20 & 9.15 & 3.33 \\
$\begin{array}{c}\text { reservoir } \\
\text { construction }\end{array}$ & Tahan Stream & 35.09 & 12.86 & 5.36 \\
Hsintien Stream & 55.43 & 23.84 & 11.10 \\
Keelung River & 25.20 & 9.15 & 3.33 \\
\hline
\end{tabular}
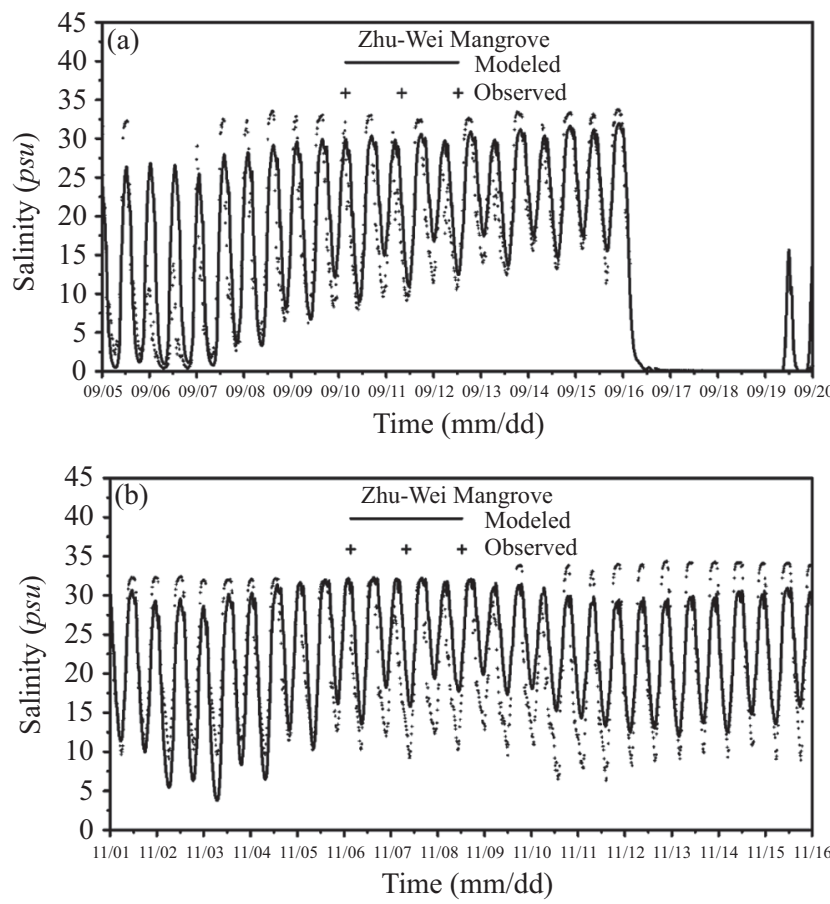

Fig. 6. Comparison of computed salinity with time series observed data during the period (a) September 5 to 19, and (b) November 1 to 15 , 2001 at Zhu-Wei Mangrove.

and phases of tidal constituents were specified to generate a time series of surface elevations at open sea boundary. A constant salinity of $35 \mathrm{psu}$ at the open sea boundary was set for model simulation. The river discharges at the tidal limits of the three major tributaries, the Tahan Stream, the Hsintien Stream and Keelung River, were conducted using annually mean flow $\left(\mathrm{Q}_{\mathrm{m}}\right), \mathrm{Q}_{50}$ flow (where $\mathrm{Q}_{50}$ is the flow that is equaled or exceeded for $50 \%$ of the time), and $\mathrm{Q}_{75}$ low flow. Table 1 lists the river discharges at upstream boundaries with mean flow, $\mathrm{Q}_{50}$, and $\mathrm{Q}_{75}$ flow before and after reservoir construction.

Figs. 7 and 8 present the predicted salinity distributions before and after reservoir construction, respectively, under $\mathrm{Q}_{75}$, $\mathrm{Q}_{50}$, and $\mathrm{Q}_{\mathrm{m}}$ flow conditions in Danshuei River-Tahan. The computed salinities were averaged over 58 tidal cycles to smooth out the spring-neap as well as intratidal variations.
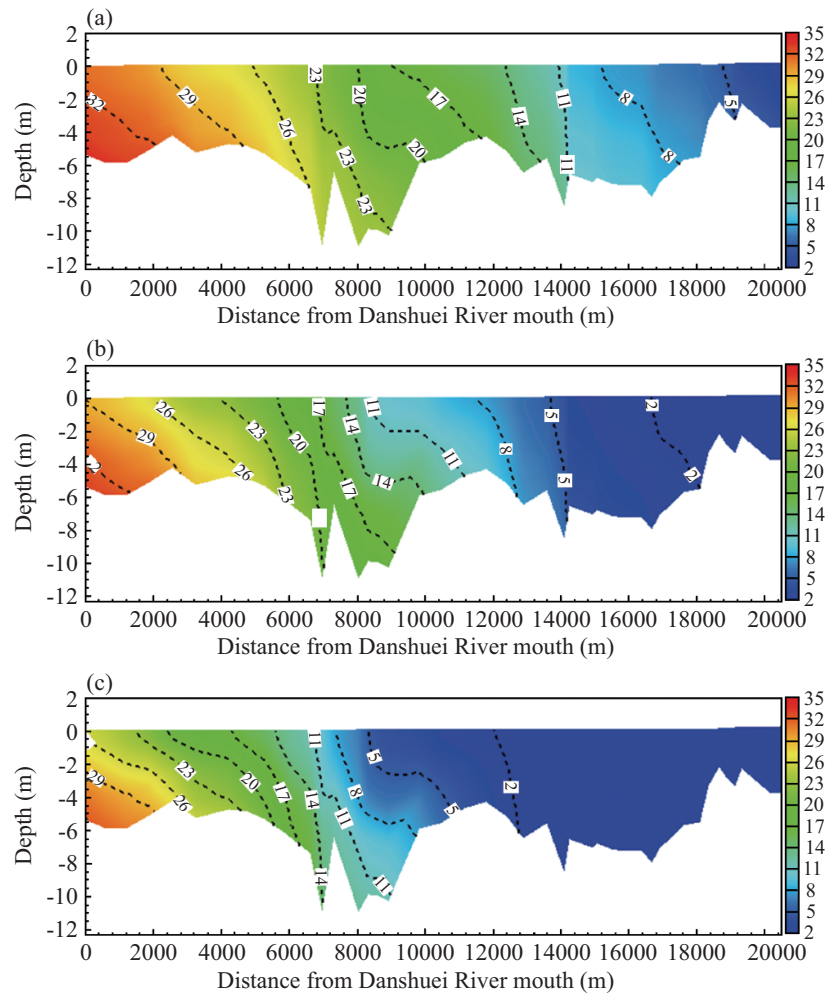

Fig. 7. Model predict of tidal average salinity distribution along the channel before reservoir construction under (a) $Q_{75}$ (b) $Q_{50}$ and (c) $Q_{m}$ flow condition in Danshuei River-Tahan Stream.
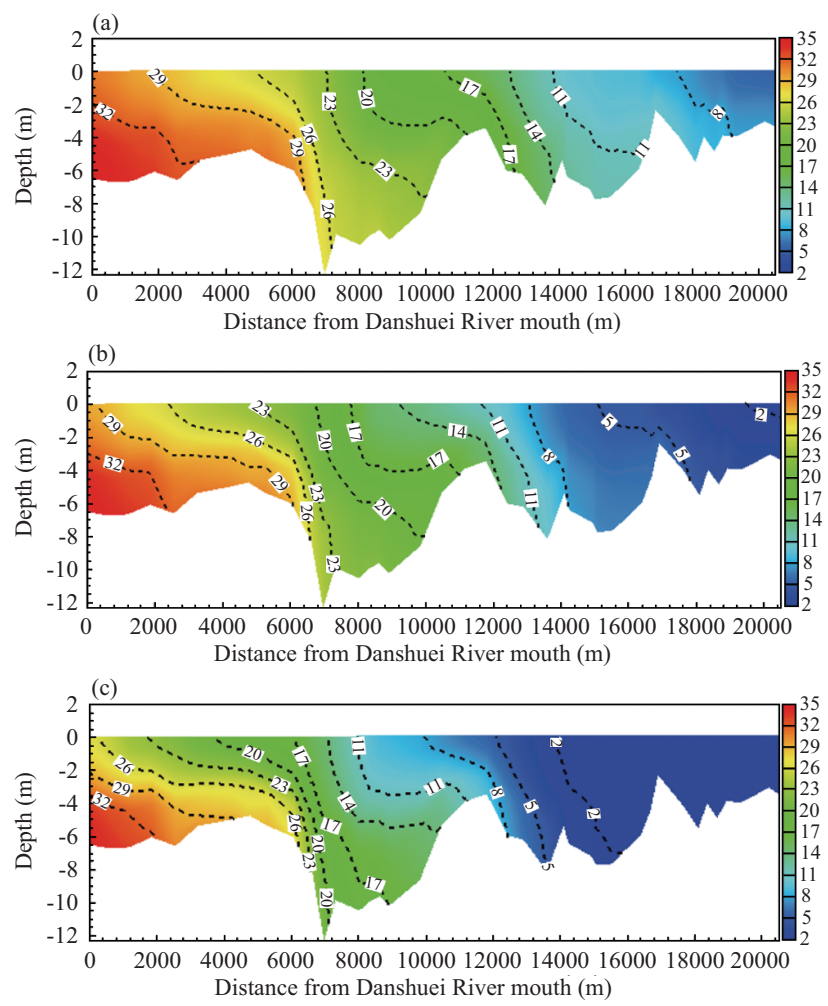

Fig. 8. Model predict of tidal average salinity distribution along the channel after reservoir construction under (a) $Q_{75}$ (b) $Q_{50}$ and (c) $Q_{m}$ flow condition in Danshuei River-Tahan Stream. 

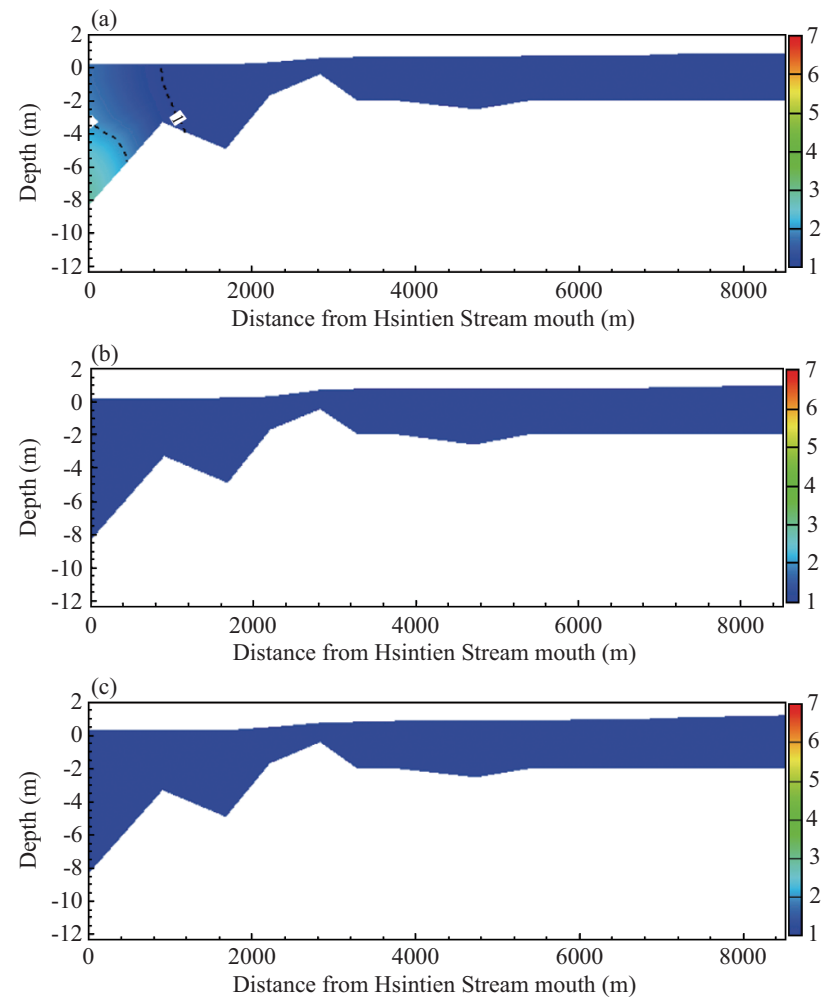

Fig. 9. Model predict of tidal average salinity distribution along the channel before reservoir construction under (a) $Q_{75}$ (b) $Q_{50}$ and (c) $\mathbf{Q}_{\mathrm{m}}$ flow condition in Hsintien Stream.
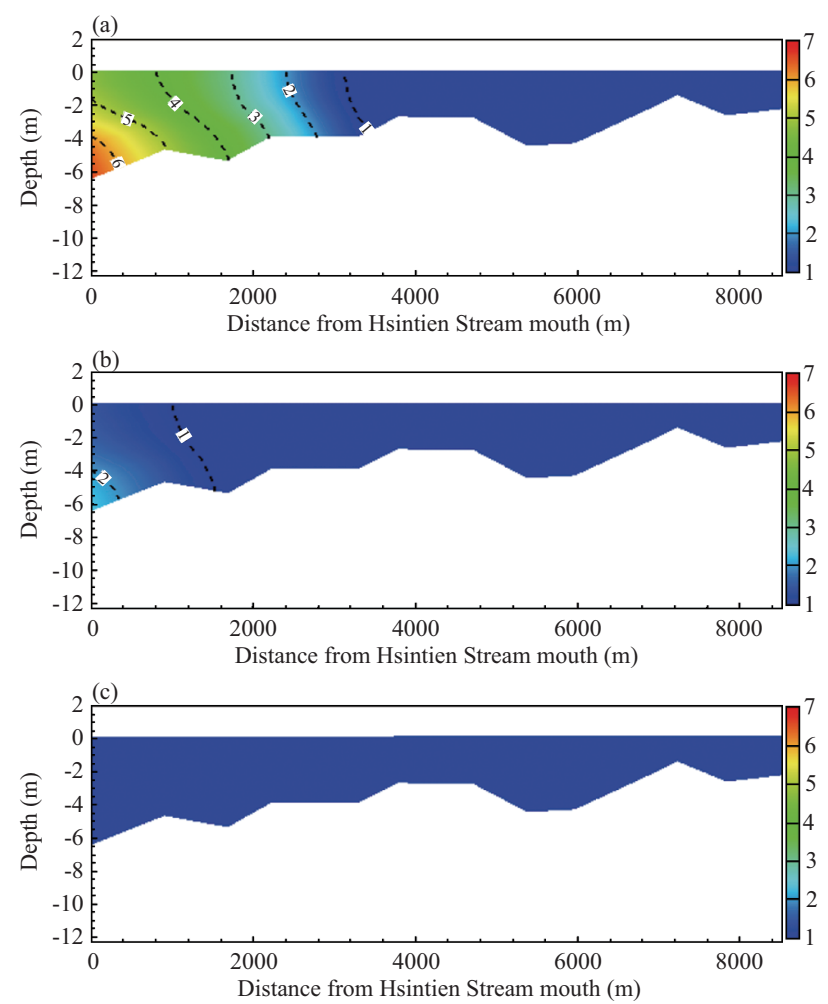

Fig. 10. Model predict of tidal average salinity distribution along the channel after reservoir construction under (a) $Q_{75}$ (b) $Q_{50}$ and (c) $\mathbf{Q}_{\mathrm{m}}$ flow condition in Hsintien Stream.
Table 2. Limit of salt water intrusion in the Tahan Stream under various river discharge conditions.

\begin{tabular}{|c|c|c|}
\hline $\begin{array}{c}\text { Limit of salt water intrusion } \\
\text { (distance from Danshuei } \\
\text { River mouth) }\end{array}$ & $\begin{array}{c}\text { Before reservoir } \\
\text { construction } \\
(\mathrm{km})\end{array}$ & $\begin{array}{c}\text { After reservoir } \\
\text { construction } \\
(\mathrm{km})\end{array}$ \\
\hline$Q_{75}$ & 23.75 & 25.85 \\
\hline$Q_{50}$ & 18.35 & 23.00 \\
\hline$Q_{m}$ & 12.90 & 16.40 \\
\hline
\end{tabular}
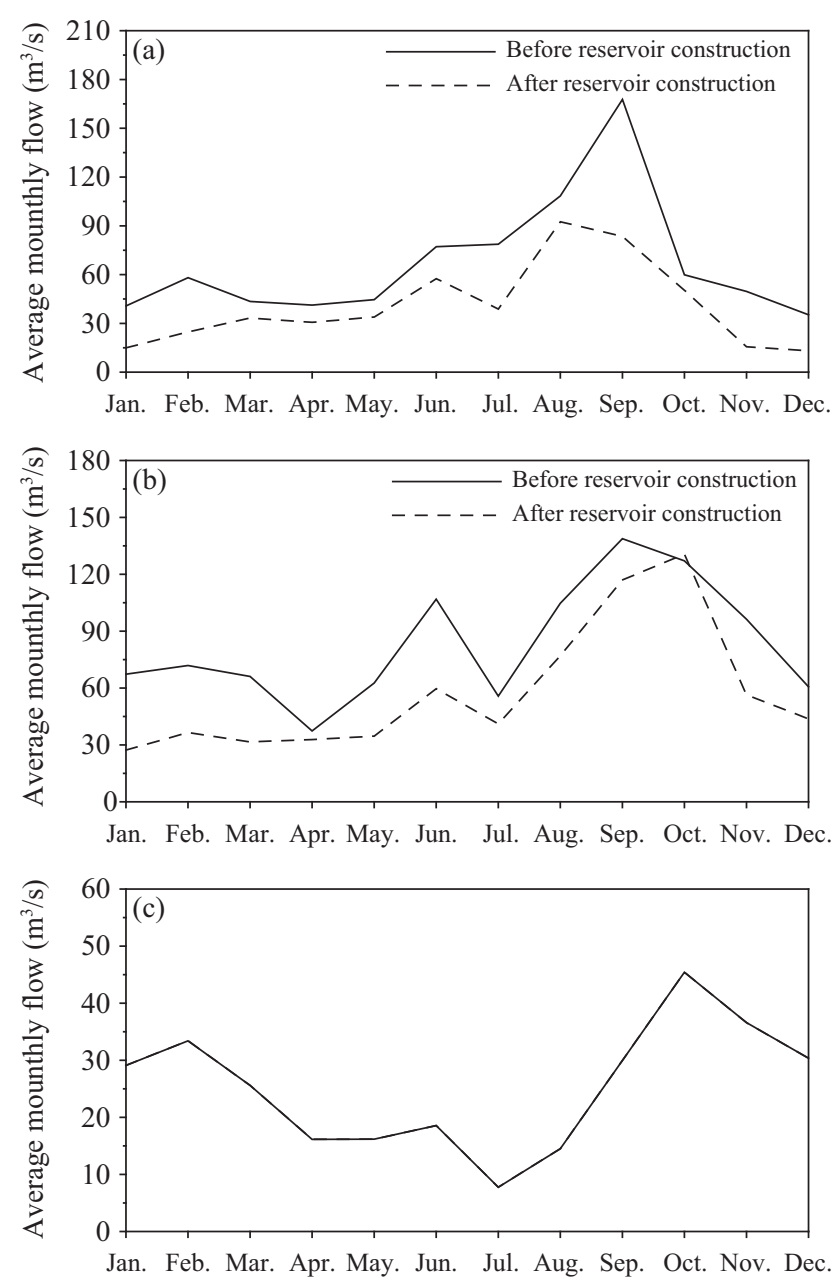

Fig. 11. Average monthly flows at the upstream boundaries of (a) Tahan Stream (b) Hsintien Stream and (c) Keelung River before and after reservoir construction.

When the river discharges increase, the limit of salt intrusion was pushed to father downriver (Fig. 7). The limits of salt intrusion after reservoir construction were farther up-river than that before reservoir construction in the Danshuei RiverTahan Stream. The same simulated results also appeared in the Hsintien Stream before and reservoir construction (see Figs. 9 and 10). This reflects the combined effects of the reduction in river discharges and the deepening and widening of the river. The limits of salt intrusions, represented by 1 psu 

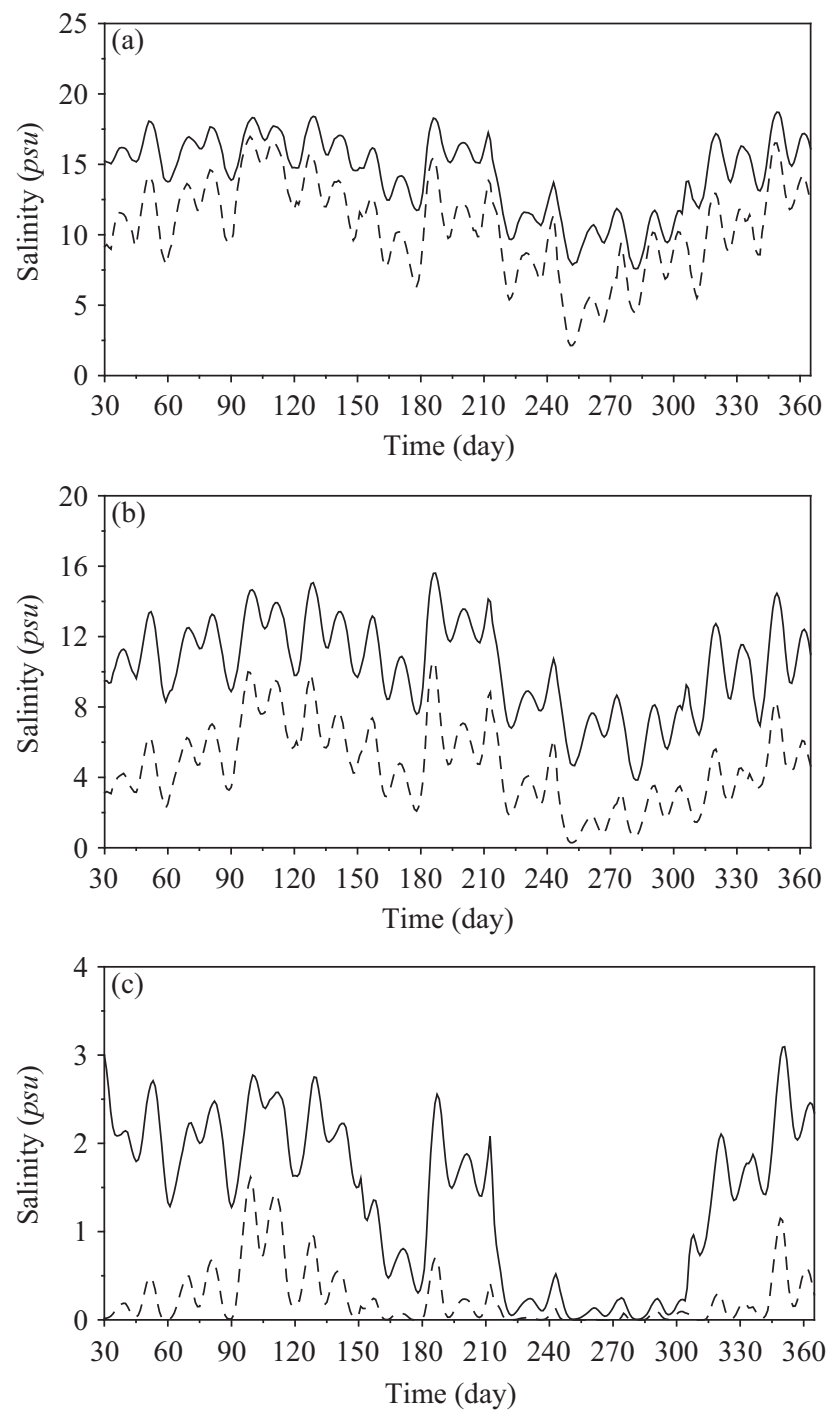

Fig. 12. Comparison of computed time series salinity in the surface layer after (solid line) and before (dashed line) reservoir construction at the (a) Kuan-Du Bridge, (b) near Kuna-Du wetland, and (c) Taipei Bridge.

isohaline, are located $12.9 \mathrm{~km}$ and $16.4 \mathrm{~km}$ from the Danshuei River mouth in the Tahan Stream before and after reservoir construction, respectively, under $\mathrm{Q}_{\mathrm{m}}$ discharge. The estuarine circulation is mainly consists of rive runoff and density-driven circulation, the former is wakened due to the reduced river discharge by the reservoirs, and the later is stronger due to the enhanced salt water intrusion. Table 2 presents the summary results of the salt intrusion in the Tahan Stream under various discharge conditions.

To examine the salinity change under the seasonally varying river discharge condition, another set of model simulations were conducted using average monthly discharges before and after reservoir construction. Fig. 11 presents the average monthly flows at upstream boundaries of the three tributaries. It shows that the average monthly flows in the Tahan Stream and Hsintien Stream are significantly reduced after the reser-
Table 3. Annual mean salinities before and after reservoir construction.

\begin{tabular}{|c|c|c|c|}
\hline Condition & $\begin{array}{c}\text { Kuan-Du } \\
\text { Bridge (psu) }\end{array}$ & $\begin{array}{c}\text { Near Kuan-Du } \\
\text { wetland (psu) }\end{array}$ & $\begin{array}{c}\text { Taipei Bridge } \\
(\mathrm{psu})\end{array}$ \\
\hline $\begin{array}{c}\text { Before reservoir } \\
\text { construction }\end{array}$ & 10.6 & 4.6 & 0.2 \\
\hline $\begin{array}{c}\text { After reservoir } \\
\text { construction }\end{array}$ & 14.3 & 10.3 & 1.4 \\
\hline
\end{tabular}

voirs were constructed. The flows in the Keelung River were unchanged, since no reservoir was constructed there.

Fig. 12 illustrates the simulation results of time-series salinity variation in the surface layer at the Kuan-Du Bridge, near the Kuan-Du wetland, and Taipei Bridge. The salinity fluctuates in response to the variation of average monthly flows. The postreservoir condition has the salinity higher than the prereservoir condition at all time. Table 3 shows the annual mean salinities before and after reservoir construction at the Kuan-Du Bridge, near the Kuan-Du wetland, and Taipei Bridge. This suggests that the long-term salinity increases have the potential to favor the development of mangrove wetlands near the Keelung River month. It has been reported that salinity increase was the major reason for the shift of vegetation types in the Kuan-Du wetland over the past thirty years $[9,10,18]$.

\section{Effect on Residual Circulation}

The current velocity in estuaries is decomposed into two components - tidal and residual. The dominant residual velocity can be often characterized by the upriver movement of more saline water in the lower layer and the downriver movement of less saline water in the upper layer [8]. To investigate the spatial and residual current, the long-term averaged velocity was obtained from the simulation results. In the case of before and after reservoir construction, the averaged residual velocities over two spring-neap tidal cycles are presented in Figs. 13 and 14, respectively. The deeper channel and reduced discharges enhance the residual circulation that pushes salt water further upstream along the lower portion of the water column. The apparent residual circulation occurs at the bottom layer in the main Danshuei river estuary and causes the current to be directed upriver. The residual circulation after reservoir construction is stronger than that before reservoir construction in the main stream of Danshuei River. This is also the reason why a large difference in salinity distribution after and before reservoir construction in the estuary.

\section{CONCLUSIONS}

A three-dimensional hydrodynamic model was performed and applied to the Danshuei River estuarine system and its adjacent coastal sea in northern Taiwan. The model was validated by comparing with measured water surface elevation, current, and salinity under variable daily freshwater discharges 


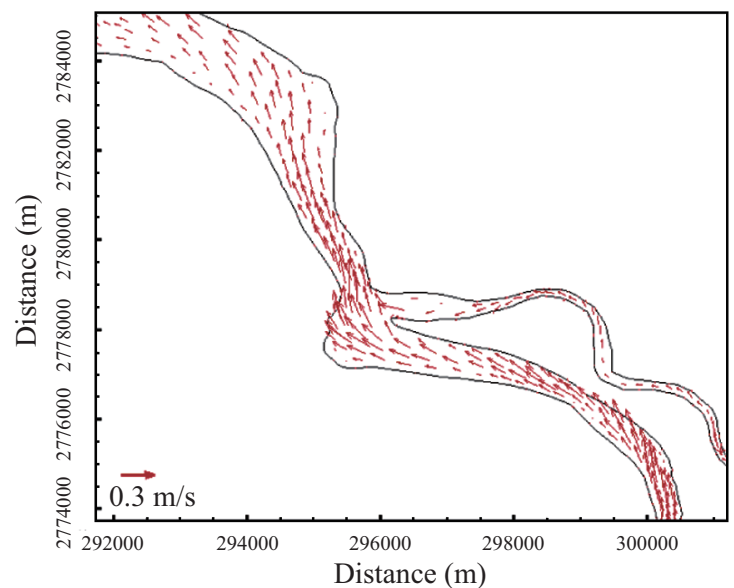

(a)

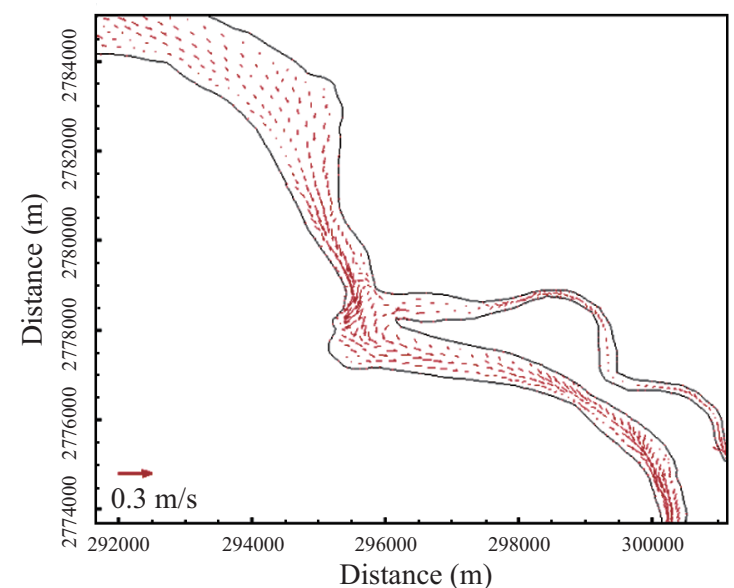

(b)

Fig. 13. Modeled residual current before reservoir construction at the (a) surface and (b) bottom layer with $Q_{75}$ flow condition.

from upper reaches of the Tahan Stream, Hsintien Stream, and Keelung River in 2001. Overall the simulated results satisfactorily agreed with measured data.

The validated model was then used to investigate the effects of reservoir constructions on salinity distributions and residual currents in the Danshuei River estuarine system. The results show that the limit of salt intrusion moved farther upriver after the reservoirs were constructed. The residual circulation after reservoir construction is stronger than that before reservoir construction in the main stream of Danshuei River. Substantial increases in salinity occurred throughout the estuary. Another set of model simulations was executed using time varying river flows at upstream boundaries. The results show that the surface salinity near Kuan-Du wetland increased at all time of the year and annual mean salinities before and after reservoir construction were 4.6 psu and 10.3 psu, respectively. The results suggest that the reservoir constructions in the upper reaches in Tahan Stream and Hsintien Stream may be the major contributory reason for the expansion of the mangrove areas and the disappearance of the freshwater marshes at the Kuan-Du wetland.

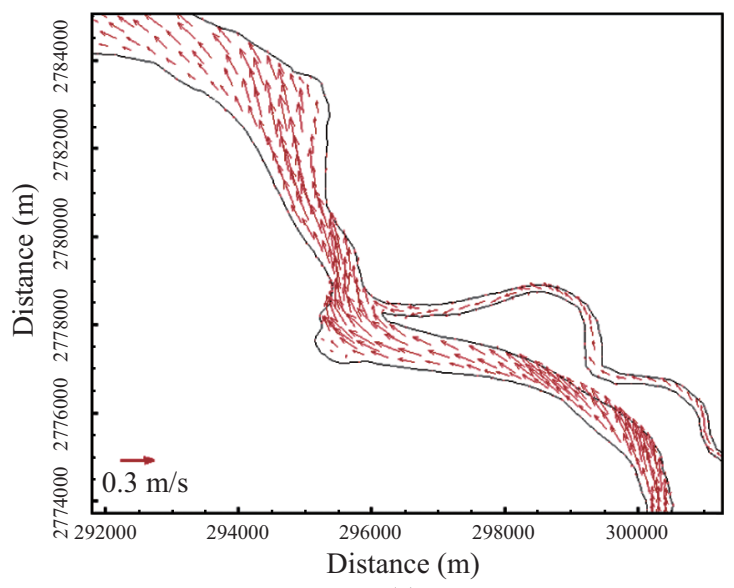

(a)

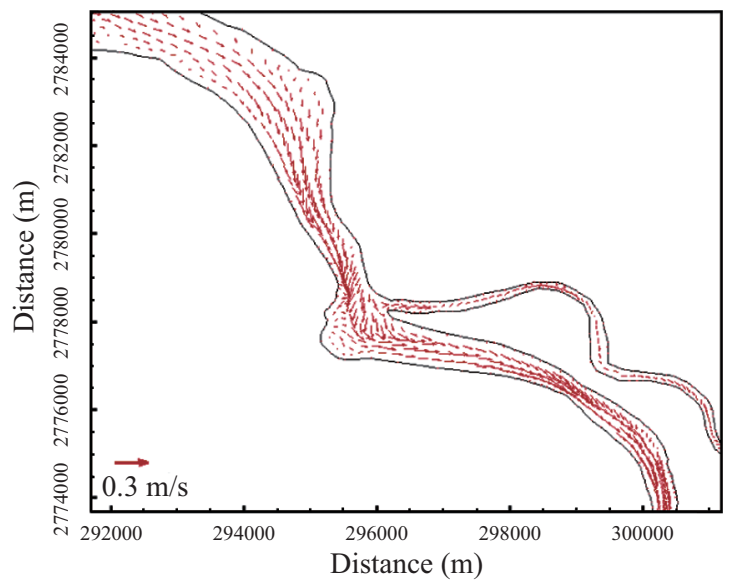

(b)

Fig. 14. Modeled residual current after reservoir construction at the (a) surface and (b) bottom layer with $Q_{75}$ flow condition.

\section{ACKNOWLEDGMENTS}

This study was supported in part by National Science Council, Taiwan, under grant No. 97-2625-M-239-001. The financial support is greatly appreciated. The authors also thank the Taiwan Water Resources Agency for providing the measured data for model validation.

\section{REFERENCES}

1. An, Q., Wu, Y., and Taylor, S., "Influence of the Three Gorges project on saltwater intrusion in the Yangtz River Estuary," Environmental Geology, Vol. 56, No. 8, pp. 1679-1686 (2008).

2. Cheng, R. T., Burau, J. R., and Gartner, J. W., "Interfacing data analysis and numerical modeling for tidal hydrodynamic phenomena," in: Parker, B B. (Ed.), Tidal Hydrodynamics, Wiley, New York, pp. 201-219 (1991).

3. Hanert, E., Deleersnijder, E., Blaise, S., and Remacle, J., "Capturing the bottom boundary layer in finite element ocean models," Ocean Modelling, Vol. 17, pp. 153-162 (2007).

4. Hsu, M. H., Kuo, A. Y., Kuo, J. T., and Liu, W. C., "Procedure to calibrate and verify numerical models of estuarine hydrodynamics," Journal of Hydraulic Engineering, ASCE, Vol. 125, pp. 166-182 (1999).

5. Huang, W. and Spaulding, M., "Modelling residence-time response to 
freshwater input in Apalachicola Bay, Florida, USA," Hydrological Processes, Vol. 16, pp. 3051-3064 (2002).

6. Kjerfve, B., "The Santee-Cooper: A study of estuarine manipulations," in: Wiley, M. (Ed.), Estuaries Process, Vol. 1, Academic, Orlando, FL, pp. 44-56 (1976).

7. Kjerfve, B. and Greer, J. E., "Hydrography of the Santee River during moderate discharge conditions," Estuaries, Vol. 1, pp. 111-119 (1978).

8. Liu, W. C., "Modeling circulation and vertical mixing in estuaries," Proceedings of the Institute of Civil Engineers, Maritime Engineering, Vol. 159 , pp. 67-76 (2006).

9. Liu, W. C., "Effects of channel regulation on salt intrusion and residual circulation of Keelung River," Hydrological Processes, Vol. 19, pp. 40394054 (2005).

10. Liu, W. C., Hsu, M. H., and Wang, C. F., "Modeling of flow resistance in mangrove swamp at mouth of tidal Keelung River, Taiwan," Journal of Waterway, Port, Coastal and Ocean Engineering, ASCE, Vol. 129, pp. 86-92 (2003).

11. Mao, X., Jiang, W., Zhao, P., and Gao, H., "A 3-D numerical study of salinity variations in the Bohai Sea during the recent years," Continental Shelf Research, Vol. 28, pp. 2689-2699 (2008).

12. McAlice, B. J. and Jaeger, Jr. G. B., "Circulation changes in the Sheepscot River Estuary, Maine, following removal of a causeway," Estuaries, Vol. 6, pp. 190-199 (1983).

13. Oliverira, A., Fortunato, A. B., and Rego, J. R. L., "Effect of morphological changes on the hydrodynamics and flushing properties of Obidos Lagoon (Portugal)," Continental Shelf Research, Vol. 26, pp. 917-942
(2006).

14. Pond, S. and Pickard, G. L., Introductory Dynamic Oceanography, Butterworth-Heinmann, London (1998).

15. Sierra, J. P., Sanchez-Arcila, A., Figueras, P. A., Gonzalez Del Rio, J., Rassmussen, E. K., and Mosso, C., "Effects of Discharge Reductions on Salt Wedge Dynamics of the Ebro River," River Research and Applications, Vol. 20, pp. 61-77 (2004)

16. Tennekes, H., "The logarithmic wind profile," Journal of the Atmospheric Science, Vol. 30, pp. 234-238 (1973).

17. Umlauf, L. and Buchard, H., "A generic length-scale equation for geophysical turbulence models," Journal of Marine Research, Vol. 61, pp. 235-265 (2003)

18. Wester, L., Vegetation change in Kuan-Du marsh, Taiwan 1978-1985, Detailed Planning of Kuan-Du National Park, Taipei City Government, Taipei, pp. 415-426 (1988)

19. Zeng, Z., Zhao, M., and Dickinson, R. E., "Intercomparison of bulk aerodynamic algorithms for the computation of sea surface fluxes using TOGA COARE and TAO data," Journal of Climate, Vol. 11, pp. 26282644 (1998).

20. Zhang, Y. L. and Baptista, A. M., "SELFE: A semi-implicit EulerianLagrangian finite-element model for cross-scale ocean circulation with hybrid vertical coordinates," Ocean Modelling, Vol. 21, pp. 71-96 (2008a).

21. Zhang, Y. L. and Baptista, A. M., "An efficient and robust tsunami model on unstructured grids. Part I: Inundation benchmarks," Pure and Applied Geophysics, Vol. 165, pp. 2229-2248 (2008b). 